\title{
Adding 3 dose artesunate to pyrimethamine sulfadoxine reduced treatment failure in children with acute uncomplicated malaria
}

von Seidlein L, Milligan P, Pinder M, et al. Efficacy of artesunate plus pyrimethamine-sulphadoxine for uncomplicated malaria in Gambian children: a double-blind, randomised, controlled trial. Lancet 2000 Jan 29;355:352-7.

QUESTION: In Gambian children with acute uncomplicated malaria, is pyrimethamine sulfadoxine (PS) and artesunate more effective than PS alone for Plasmodium falciparum malaria?

Design

Randomised (allocation concealed*), blinded (patients, parents, and investigators), ${ }^{*}$ placebo controlled trial with 28 day follow up.

Setting

5 health centres in the Gambia ( 1 in a semiurban coastal area and 4 in the rural inland region).

\section{Patients}

600 children who were $<10$ years of age (mean age $5 \mathrm{y}$, $52 \%$ boys), weighed $>5 \mathrm{~kg}$, were infected with $P$. falciparum at a density of $\geqslant 500 / \mu \mathrm{l}$, had a history of fever, and lived within $20 \mathrm{~km}$ of a trial centre. Exclusion criteria were requirement for parenteral treatment, treatment within the previous 2 weeks with PS, a haematocrit concentration $<15 \%$, or evidence of chronic disease. Follow up was $95 \%$ at 14 days and $94 \%$ at 28 days.

\section{Intervention}

Children were allocated to 1 of 3 groups: PS plus placebo $(\mathrm{n}=200)$; PS plus 1 dose of artesunate, $4 \mathrm{mg} / \mathrm{kg}$ of body weight $(\mathrm{n}=200)$; or PS plus artesunate, $4 \mathrm{mg} / \mathrm{kg}$ daily for 3 days $(n=200)$. Children received one half of a tablet of PS if their body weight was $<10 \mathrm{~kg}$ and an additional one quarter of a tablet for every $5 \mathrm{~kg}$ increment.

Source of funding:

UNDP/World

Bank/WHO Special

Programme for

Research and Training

in Tropical Diseases

(TDR).

For correspondence:

Dr L von Seidlein,

International Vaccine

Institute, Seoul

National University

Campus, Shillim-Dong,

Kwahak-gu, Seoul

151742, Korea.

\section{Main outcome measures}

Tolerability, safety, and treatment failure (if rescue treatment was required or the patient was parasitemic) at 14 days and 28 days.

\section{Main results}

No severe adverse reactions attributable to treatment occurred. Fewer children in the 3 dose artesunate group than in the PS alone group needed rescue treatment or were parasitemic at 28 days $\{\mathrm{p}<0.02\} \dagger$ (table). No differ-

Treatment failure rates for pyrimethamine sulfadoxine (PS) and artesunate (1 dose [Art-1] or 3 doses [Art-3]) v PS alone for acute uncomplicated malaria in children

\begin{tabular}{|c|c|c|c|c|}
\hline Follow up & Comparison & Event rates & RRR (95\% Cl) & NNT (Cl) \\
\hline 14 day & $\mathrm{PS}+$ Art-3 $v \mathrm{PS}$ & $1.6 \% v 3.1 \%$ & $49 \%(-84$ to 86$)$ & Not significant \\
\hline \multirow[t]{3}{*}{28 day } & PS + Art-3 v PS & $2.1 \% \vee 7.3 \%$ & $71 \%(17$ to 90$)$ & $20(10$ to 104$)$ \\
\hline & $\mathrm{PS}+$ Art-1 $v \mathrm{PS}$ & $7.0 \% \vee 7.3 \%$ & $4 \%(-95$ to 53$)$ & Not significant \\
\hline & & & RRI (Cl) & NNH \\
\hline $14 \mathrm{~d}$ & $\mathrm{PS}+$ Art-1 $v \mathrm{PS}$ & $3.7 \%$ v $3.1 \%$ & $20 \%(-57$ to 234$)$ & Not significant \\
\hline
\end{tabular}

‡Abbreviations defined in glossary; RRR, RRI, NNT, NNH, and $\mathrm{Cl}$ calculated from data in article.

ences in treatment failure existed between the 2 artesunate groups and the PS alone group at 14 days or between the 1 dose artesunate and PS alone groups at 28 days (table).

\section{Conclusion}

In Gambian children with acute uncomplicated malaria, pyrimethamine sulfadoxine and 3 doses of artesunate led to fewer treatment failures at 28 days than did pyrimethamine sulfadoxine alone.

*See glossary.

tp Value calculated from data in article.

\section{COMMENTARY}

Chloroquine and PS are the most widely used antimalarial agents in sub-Saharan Africa, but resistance to these drugs is emerging. If a healthcare catastrophe is to be avoided, alternative treatments are urgently needed. In southeastern Asia, combination treatment with artesunate has been shown to improve the therapeutic efficacy of mefloquine, ${ }^{1}$ and may slow the emergence of drug resistance. ${ }^{2}$ Von Seidlein et al are the first to study a combination regimen of artesunate with PS.

Although the trial was done in an area where PS still has good efficacy, the addition of 3 doses of artesunate resulted in a substantially faster therapeutic response and higher cure rate at day 28. Patients who received artesunate (1 or 3 doses) were also less likely to carry gametocytes (the sexual stage of the parasite) during recovery than were those treated with PS alone (23\% v 67\% at 7 d). The introduction of atermisinin derivatives in combination with PS may therefore decrease P.falciparum transmission.

The fact that artesunate plus PS was well tolerated and highly efficacious and resulted in reduced gametocyte carriage supports the growing opinion that antimalarial drugs should no longer be used alone but only in combination with an artemisinin derivative. ${ }^{3}$ The results of further studies combining artesunate with other antimalarial drugs are awaited.

Richard N Price, MD John Radcliffe Hospital Oxford, $U K$

1 Nosten F, Luxemburger C, ter Kuile FO, et al. Treatment of multidrug-resistant Plasmodium falciparum malaria with 3-day artesunate-mefloquine combination. J Infect Dis 1994; 170:971-7.

2 White NJ. Preventing antimalarial drug resistance through combinations. Drug Resistance Updates 1998;1:3-9.

3 White NJ, Nosten F, Looareesuwan S, et al. Averting a malaria disaster. Lancet 1999;353:1965-7. 